\title{
BULLYING ESCOLAR: UM CONFLITO QUE CRESCE E APARECE
}

Gisele Dayane Milani ${ }^{1}$, Luci Martins Barbatto Volpato ${ }^{2}$

${ }^{1}$ Discente do curso de Serviço Social das Faculdades Integradas "Antônio Eufrásio de Toledo" de Presidente Prudente. 2Docente do curso de Serviço Social das Faculdades Integradas "Antônio Eufrásio de Toledo" de Presidente Prudente. E-mail: giselemilani@hotmail.com

\section{RESUMO}

O presente artigo tem por objetivo apresentar e discorrer sobre o Bullying, fenômeno tão debatido no cenário atual, principalmente em relação aos excessos realizados pela mídia e pela população em geral, generalizando o termo. O fenômeno Bullying é caracterizado por atos de agressão e desrespeito, denominado de ataque e se manifesta com ações repetitivas contra uma outra pessoa. Tema polêmico e desafiante, pois não pode apenas ser combatido com repressão, pois dessa forma atuar-se-ia somente na consequência do problema.

Palavras-chave: Bullying. Autor. Alvo. Política de Educação.

\section{INTRODUÇÃO}

Este trabalho teve por objetivo apresentar fenômeno Bullying, fruto de pesquisas sobre um tema atual e acirrado pelo contexto social contemporâneo, marcado pelo individualismo, que ganha assim, fácil repercussão pela mídia.

O Bullying é caracterizado com atos de agressão e desrespeito. Para ser considerado como tal, é necessário existir o agressor denominado autor, a vítima denominada alvo e quem assiste as cenas, denominado expectador. E ainda, com atos praticados cotidianamente. De acordo com esses parâmetros, este artigo segue o com uma apresentação sobre o conceito e origem dos estudos de Bulllying, os tipos de Bullying e destacado o Bullying escolar, tema da pesquisa. Em seguida foram descritos os personagens que participam do Bullying, quem maltrata, quem sofre e quem assiste aos ataques.

A pesquisa utilizou como metodologia para o estudo sobre o Bullying o método dedutivo, pois partiu de seu conceito e explicitação no geral para a discutir o Bullying. Como método assessório foi utilizado o método histórico, visando descrever rapidamente sobre a origem dos estudos de Bullying e o método monográfico, pois foi realizado um estudo geral sobre o temo e suas repercussões. Como técnicas, foram utilizadas pesquisas bibliográficas, em artigos, publicações, informações coletadas em sala de aula e em material eletrônico. E ainda, a pesquisa tem como particularidade ser explicativa, pela razão de descrever e identificar os casos de ataque de Bullying, suas características e considerações sobre o autor e alvo. 


\section{CONCEITO E ORIGEM DOS ESTUDOS SOBRE O BULLYING}

O fenômeno Bullying é caracterizado por atos de agressão e desrespeito, denominado de ataque e se manifesta com ações repetitivas contra uma outra pessoa. A intimidação e o ataque são praticados pelo agressor, denominado de autor de bullying e contêm a intenção de maltratar ou causar tensão e angústia em uma vítima chamada de alvo de bullying, geralmente o gordinho, o baixinho, o altinho, ou seja, quem se destaca.

Atualmente, a mídia exalta o tema e generaliza diversas ações e violências como Bullying. Mas, para ser considerado como tal, são necessárias algumas características. De acordo com a cartilha do Ministério Público que Bullying não é Legal (s.d;p. 2), este caracteriza-se por atos físicos, verbais, morais ou sexuais, de forma voluntária e repetitiva, tendo um autor, alvo e expectadores que funcionam como platéia expectadora para assistir as cenas.

De acordo com Olwels (2004, 17-18), no final da década de 70, iniciou-se na Suécia o interesse da sociedade pelos agressores e vítimas, do que mais tarde foi denominado Bullying. O que mais chamou a atenção de Olwels, professor da Universidade de Bergen na Noruega, foi o número expressivo de suicídios ocorridos em crenças nesta década e cidade. A partir de então, iniciaram-se estudos e desenvolveram-se os primeiros critérios visando detectar a forma específica do tema. No Brasil, segundo Fante (2008, p.9), o tema chegou ao final da década de 90 e início do ano 2000, como reflexo do movimento que estava ocorrendo. Assim, apesar da atual repercussão do Bullying na sociedade, como pode ser notado, não é um fenômeno novo. $O$ problema é que ele está se ampliando e se modificando, adquirindo novas manifestações e novas formas de ataques vão surgindo, cada vez mais violentas.

Nesse sentido, Fante (2008, p.2-3), “Alguns fatores propiciam o bullying, sua banalização e legitimização, como: atitudes culturais, como o desrespeito, a intolerância, a desconsideração ao "diferente";". Assim como, a hierarquização das relações; a popularidade e a manutenção do status; comportamento abusivo; manter silêncio ao invés de denunciar; o incentivo de quem assiste às ações cruéis e desumanas; a violência doméstica, permissividade familiar; a omissão e o despreparo das pessoas que lidam com o assunto; a carência de investimentos em políticas públicas para a prevenção, dentre outros são desafios e serem supridos. Nesse sentido, o Bullying difere-se da violência, mas sua prática não deixa de ser uma forma de violência. As ações violentas são ocasionais e reativas. O bullying, no entanto, é caracterizado por ações repetitivas de um autor contra a vítima e com espectadores. 


\section{TIPOS DE BULLYING E O BULLYING ESCOLAR}

Existem vários tipos de Bullying, cada um com suas peculiares e características. De acordo com Calhau (2010 s.p), existem o Bullying Escolar, o Ciberbullying, o Bullying no Trabalho, o Bullying Homofóbico, o Bullying Militar, o Bullying Prisional, o Bullying Assédio Sexual e Stalking. Quanto as formas de bullying, estas podem ser verbal, física e material, psicológica e moral, sexual e virtual.

O Bullying Escolar é um fato presente e comum na maioria das escolas com crianças e adolescentes. Segundo Calhau (2010, p.27), a "Falta de educação e respeito com colegas e professores são muito comuns hoje no sistema escolar." Muitos relatos desse fenômeno são evidenciados cotidianamente pela mídia. Assim, a negação das ações e as justificativas das "zuações", caracterizam a crueldade dos autores de bullying. O "zuar" esconde ações violentas, manifestadas no ambiente escolar e que a escola "finge" não ver. Comumente, a escola vai responsabilizar e culpabilizar a família do autor do bullying, suspender este das aulas, ou adotar medidas, que muitas vezes são ineficientes para resolver à problemática.

No que tange os pais e/ou responsáveis pelos autores e vítimas, de acordo com Calhau (2010, p. 27-28), estes "não conseguem delimitar de forma clara as fronteiras entre o que se pode e o que não se pode fazer, eles se tornam incapazes de exercer uma ação educativa eficaz". Percebe-se que a família também está sem parâmetros, muitas vezes também está sendo vitimizada, ou dependendo da cultura, entende essa manifestação como um "rito de passagem". E ainda, se o filho dela for o agressor para ela está tudo bem, pois é valentão, o homem da casa.

\subsection{Dos Personagens: Quem Maltrata, Quem Sofre e Quem Assiste}

Os agressores podem ser do sexo feminino e masculino. Podem agir sozinhos como mandões do território ou em grupo, o que possibilita ampliar seu local de domínio. Os tipos de agressões diferem entre as praticadas por meninos e meninas. Quanto ao sexo masculino, este tende a utilizar mais a força física nos ataques de bullying. Com relação às agressoras femininas, estas utilizam mais ataques morais, como fofocas, intrigas, mentiras etc.; porém são bem elaboradas e complexas.

Em atos de Bullying, as vítimas dos ataques são chamadas de alvo. Normalmente se destacam no meio em que estão inseridas, são: gordinhos, magros, altos ou baixos de mais, orelhas ou nariz mais destacados, usam óculos, ou seja quem foge dos padrões de beleza e estética da sociedade. Os personagens da trama do bullying são alunos e pessoas que assistem, 
como espectadores, aos atos praticados contra o alvo e não tomam nenhuma atitude ou providência, apenas observam.

As consequências dos atos são negativas tanto para o alvo, para os expectadores, que presenciam as cenas de violência, os insultos, as humilhadores e contribuindo direta e indiretamente, quanto à família que pode sofrer juntamente com o dano resultante dessa prática.

\section{A EDUCAÇÃO RESPONSABILIDADE LEGAL DA INSTITUIÇÃO ESCOLAR PELOS ATOS DE BULLYING}

A educação é um dos processos da vida social. Compreendida em sua totalidade histórica, é expressão de lutas sociais e conjunto de práticas educacionais. Assim, para Almeida (2000, s.p), “A educação como dimensão da vida social possui um caráter ontológico, ou seja, construtivo dos modos de existência humana, do ser social, da organização da vida em sociedade".

É possível afirmar que a educação está presente a todo o momento, em todos os indivíduos e em todos os lugares. O conhecimento é participe do processo de desenvolvimento humano, é "o grande capital da humanidade" (GADOTTI, 2000, s.p). Realiza-se no âmbito familiar, em instituições religiosas, comunidades e principalmente em escolas e universidades. No tange a regulamentação legal, o processo de construção da Política de Educação foi resultado de lutas sociais para que fosse reconhecida como direito social, garantida pela Lei no 9.394 de 1996.

A instituição de ensino possui responsabilidades quanto aos atos de Bullying. Os excessos de brincadeiras no âmbito escolar demonstram a face cruel de muitos alunos e muitas ações estão sendo caracterizadas como bullying. No entanto, a atuação escola na resolução de conflitos não é tarefa fácil, vez que os professores são profissionais capacitados para ministrar aulas, mas acabam, de certa forma, gastando esse tempo para resolver problemas que ora se apresentam.

O Bullying é considerado um ato infracional, sancionado pelo Estatuto da Criança e do Adolescente - ECA, porém não é especificado com esse termo. Calhau (2010, p.42), portanto plausível a ser submetido a ação junto à Vara da Infância e Juventude. O que evidencia a necessidade de articulação da rede de ensino com as instâncias jurídicas e rede de serviços do município, visando à intervenção no fenômeno.

\section{CONSIDERAÇÕES FINAIS}

A partir das discussões elencadas nesse trabalho, foi possível discutir sobre o Bullying, fenômeno tão debatido no cenário atual. A crítica, no entanto, é feita em relação aos 
excessos que se faz pela mídia e população em geral, que apontam tal fenômeno em todas as situações em que houver conflito, generalizando o termo.

A política educacional foi historicamente determinada pela oferta de serviços educacionais, com práticas que envolvem professores e direção escolar. A educação deve ser pensada além da prática das escolas, enquanto amplo espaço que ocorre em todo lugar e a todo tempo.

Como resultado dessa pesquisa, é possível traçar um caminho no que tange o enfrentamento da temática. Em um primeiro momento é necessário um diagnóstico para a identificação dos problemas que se destacam no ambiente escolar.

Para intervenção do problema, são necessárias articulações entre instituições, principalmente a escola, a família e o Ministério Público. Este último vai ser essencial, pois funciona como mecanismo de garantia de direitos a crianças e adolescentes. A escola, enquanto instituição de socialização de ensino e aprendizagem também necessita de regras a fim de uma convivência harmônica e devem promover programas antibullying. Cabe mencionar também o papel do Conselho Tutelar no município, pois é este órgão que mantem contato direto com as escolas e com a rede de serviços do município, ou seja, é um órgão requisitado na intervenção direta dessa demanda.

Como foi possível observar ao longo da pesquisa, o bullying é um fenômeno complexo e ultrapassa métodos de combate simplistas e apenas a atuação da escola e professores. O fenômeno não deve ser tratado isoladamente, ou seja, deve ser enfrentado com programas e medidas preventivas e restaurativas, e de acordo com as circunstâncias com a ferramenta penal.

O bullying não pode apenas combatida com repressão, pois dessa forma atuar-se-ia somente na consequência do problema. O desafio, no entanto, está presente no reconhecimento de fatos e questões complexas existentes no universo escolar em cada nível de ensino e faixa etária correspondentes. É necessário estimular o debate sobre o bullying dentro da sala de aula, se possível envolver o a comunidade e chamar profissionais da rede de serviços do município para desenvolverem palestras e atividades.

\section{REFERÊNCIAS BIBLIOGRÁFICAS}

ALMEIDA, Ney Luiz Teixeira de. O Serviço Social na Educação: novas perspectivas sócioocupacionais. 2010. Disponível em: http://serviosocialemgeral.blogspot.com/2010/04/o-servicosocial-na-educacao-novas.html. Acesso em: 16 de outubro de 2011. 
BULLYING NÃo É LEGAL. Ministério Público do Estado de São Paulo. Disponível em: http://www.mp.sp.gov.br/portal/page/portal/Cartilhas/bullying.pdf. Acesso em: 16 de outubro de 2011.

CALHAU, Lélio Braga. Bullying: o que você precisa saber : identificação, prevenção e repressão. 3 . ed., rev., ampl. e atual. Niterói: Impetus, 2011. 137 p.

FANTE, Cleo; PEDRA, José Augusto. Bullying escolar: perguntas \&respostas. Porto Alegre: Artmed, 2008. ISBN 978-85-363-1366-5. Disponível em:

http://pt.scribd.com/doc/23442037/Bullying-escolar-perguntas-e-respostas-Versao-sem-figuras. Acesso em: 12 de outubro de 2011.

GADOTTI, Moacir. PERSPECTIVAS ATUAIS DA EDUCAÇÃO. vol.14 no.2 São Paulo Apr./June 2000. Disponível em: http://www.scielo.br/scielo.php?pid=S0102-

88392000000200002\&script=sci_arttext. Acesso em: 16 de outubro de 2011.

LEI № 8.069, DE 13 DE JULHO DE 1990. Estatuto da Criança e do Adolescente. Disponível em: http://www.planalto.gov.br/ccivil_03/leis/L8069.htm. Acesso em 12 de outubro de 2011.

LEI № 9.394, DE 20 DE DEZEMBRO DE 1996. Estabelece as diretrizes e bases da educação nacional. Disponível em: http://www.planalto.gov.br/ccivil_03/leis/L9394.htm. Acesso em: 16 de outubro de 2011.

OLWELS, Dan. Conductas de Acoso y Amenaza entre Escolares. Disponível em: http://books.google.com.br/books?id=SOwSk71uQz0C\&printsec=frontcover\&dq=conductas + de $+a c$ oso+y+amenaza+entre+escolares\&hl=pt-

BR\&ei=HOWWTsCFDOX00gHmifjRBw\&sa=X\&oi=book_result\&ct=result\&resnum=1\&ved=0CCwQ6 AEWAA\#v=onepage\&q\&f=false. Acesso em: 12 de outubro de 2011. 